\title{
ASSESSMENT OF TECHNOLOGY VS ENVIRONMENTAL REGULATIONS IN CHINA BASED ON DEA MALMQUIST MODEL AND PORTER HYPOTHESIS
}

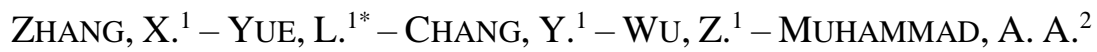 \\ ${ }^{1}$ School of Economics \& Management, Northwest University, Xi'an 710127, China \\ ${ }^{2}$ Department of Geology, Faculty of Science, University of Malaya \\ 50603 Kuala Lumpur, Malaysia \\ *Corresponding author \\ e-mail: yueliping2@sina.com \\ (Received $15^{\text {th }}$ Jun 2018; accepted $2^{\text {nd }}$ Aug 2018)
}

\begin{abstract}
Serious environmental pollution due to the economic boom in China has forced the government to implement environmental regulations. This paper examines the relationship between environmental regulations and technological development in different regions of China. Industry data from 1999 to 2012 using the DEA (Data Envelopment Analysis)-Malmquist productivity index were analyzed. It was found that total productivity growth is mainly caused by the change in technological progress. The environmental regulations of industry had a positive effect on technical progress at the national level. However, the relationship between environmental regulation and technological progress showed significant differences at the regional level. Results showed that for every $1 \%$ increase in strength of environmental regulation, there was a corresponding $7.04 \%$ increase in technology progress in eastern China. However, in central and western China, results showed that for every $1 \%$ increase in strength of environmental regulation, technology progress declined by $4.91 \%$ and $1.08 \%$, respectively. It is concluded that the Porter hypothesis is well supported by data from the advanced eastern regions, while not fully supported by data from the underdeveloped central and western regions. For the central and western regions, various reasons for deviation from the Porter Theory have been determined by using the Environmental Kuznets Curve (EKC). Policy implications such as using government allowances and bank loans to import well educated staff, to enhance production technologies, to implement environmental solutions, and to set up strict regulations are recommended for the policy makers.

Keywords: environmental regulations, technology innovations, Porter hypothesis, Malmquist DEA index, Environmental Kuznets Curve (EKC " $U$ " type relationship)
\end{abstract}

\section{Introduction}

Economic and social development in China has made remarkable achievements since reforms and increase of international relations in the late 1970s. The strong growth has injected strong vigor into the world economy, but at a price; economic development in China over consumes energy resources and decreases environmental sustainability. Therefore, the Chinese economy and society are saddled with the heavy cost of environmental protection. Meanwhile, environmental impact in China has also attracted attention from the international community (Manello, 2017). Negative impact on the environment not only restricts development of economic and social sustainability, but also has impacts at the national and political level, as the safety of people's livelihood and strategic security are affected as well. Great powers have the responsibility to carefully balance economic development with environmental protection. In 1991, Porter proposed that strict environmental protection policies can stimulate enterprise to innovate, thereby creating a so-called "innovation compensation" effect to offset the cost of investment in cleaner technologies or processes. According to the Porter 
Hypothesis, the innovation compensation effect not only offsets enterprise production costs, but may also lead to revenue increase and overall improvement in competitive advantage within the international market (Porter, 1991; Jia et al., 2013). In 1995, Porter and Linde provided further evidence to strengthen the Porter Hypothesis (Porter and Vander, 1995).

\section{Literature review}

\section{Applications of Porter's theory in the US}

The relationship between environmental regulation and technological progress used by U.S. researchers was studied. Researchers have mainly focused on the effects of various environmental regulations and, more specifically, the relationship between environmental regulation and industrial technological innovation or industry performance. The majority of studies support the Porter Hypothesis, arguing that environmental regulation has promoted economic growth due to an increased emphasis on technological innovation within an enterprise.

Research literature examining the Porter Hypothesis can be divided into the following three types:

The first type supports the Porter Hypothesis, namely, that environmental regulation has a positive effect on technological progress.

De Santis and Jona Lasinio (2016) test the narrow Porter hypothesis on a sample of European economies in the period 1995-2008. We focus on the channels through which tighter environmental regulation affect productivity and innovation. Our findings suggest that the "narrow" Porter Hypothesis cannot be rejected and that the choice of policy instruments is not neutral. In particular, market based environmental stringency measures seem to be the most suitable to stimulate innovations and productivity growth.

Ramakrishnan et al. (2017) describe a novel application of data envelopment analysis (DEA) to help extend a specific debate in the literature on Porter's hypothesis in environmental policy. The debate deals with the impact of flexibility of regulations on the relationship between innovation capabilities on financial performance in organizations. Our results indicate that innovation capabilities significantly influence financial performance of firms if firms feel that the environmental regulations they face are flexible and offer more freedom in meeting the requirements of regulations. On the other hand, corporations that feel that they face more inflexible regulations are not so effective in improving their financial performance with their innovation capabilities.

Lundgren and Zhou (2017) analyze the interactions between three dimensions of firm performance - productivity, energy efficiency, and environmental performance - and especially sheds light on the role of environmental management. We apply data envelopment analysis (DEA) technique to calculate the Malmquist firm performance indexes, and a panel vector auto-regression (VAR) methodology is utilized to investigate the dynamic and causal relationship between the three dimensions of firm performance and environmental investment. The results show that improved environmental performance and environmental investments constrain next period productivity, a result that would be in contrast with the Porter hypothesis and strategic corporate social responsibility; both concepts conveying the notion that proenvironmental management can boost productivity and competitiveness.

Exploiting the case of a German water withdrawal regulation that is managed on the state level, Ramakrishnan et al. (2017) investigate the impact of environmental 
regulation on firm performance and investment behavior and analyze firms' reactions to an increase in the water tax using a regression-adjusted difference-in-differences approach. The results imply that the predicted negative impact of the regulation on firms' economic performance that was brought up before the introduction of the tax, does not seem to weigh heavily in this case. Nevertheless, when placed into a sustainable competitiveness context, the regulation considered does not qualify as an appropriate policy tool for fostering green growth.

Antonioli et al. (2017) analyzes the environmental and economic efficiency of a sample of firms located in Italy and Germany, operating in the chemical sector and included in the European Pollution Release and Transfer Register (E-PRTR). The Directional Distance Function (DDF) approach in a conditional setting has been applied to obtain efficiency score and Total Factor Productivity (TFP) growth indexes considering pollution in computations. Emissions increase in absolute term between 2004 and 2007, with a worse performance of Italian firms, but efficiency indicators show a reduction of inefficiency over time, with similar performance of firms from the two countries. The formal test for the Porter's hypothesis suggests that chemical firms suffering higher compliance costs in the first period react with investment increasing productivity in the following years. The empirical evidence, robust to different specifications and estimation methods, supports the presence of win-win opportunities.

The second type of literature refutes the Porter Hypothesis, namely, that environmental regulation has negative effects on technological progress.

The Porter hypothesis asserts that a stricter environmental regulation stimulates firms to conduct innovation and increase their profit. Chang (2013) uses a theoretical framework to examine the Porter hypothesis. We conclude that although a stricter environmental regulation can increase profit, it does not stimulate innovation in a firm.

Albrizio et al. (2017) investigate the impact of changes in environmental policy stringency on industry- and firm-level productivity growth in a panel of OECD countries. A tightening of environmental policy is associated with a short-term increase in industry-level productivity growth in the most technologically-advanced countries. This effect diminishes with the distance to the global productivity frontier, eventually becoming insignificant. For the average firm, no evidence of $\mathrm{PH}$ is found. However, the most productive firms see a temporary boost in productivity growth, while the less productive ones experience a productivity slowdown.

Carney et al. (2017) revisit the question of family firms (FFs) and their capacity for internationalization, and link it to the literature on national competitiveness. We draw widely on the FF competitive advantage and internationalization literature to argue that FFs' organizing preferences and capabilities will typically support exporting and that these same organizing preferences will mitigate against outward FDI, two dimensions of national competitiveness. Using the logic of aggregation, we hypothesize that family firm prevalence (FFP), measured at the country level, negatively moderates a series of country-level variables associated with country outward FDI, and positively moderates a series of variables associated with country exports. We develop a unique dataset on FFP across countries using a novel method in which we extract estimates from from both published and unpublished academic studies. Our results provide consistent confirmation of the positive moderator effect of FFP on country export performance hypothesis, but contrary to expectation, higher FFP in a country has a null or positive effect on outward FDI at the country level, thus suggesting a more nuanced view of FF strengths and weaknesses. 
The third type of research explains that the effect of environmental regulation on technological progress is uncertain, neither supporting nor refuting the Porter Hypothesis.

Antonioli et al. (2013) investigate whether firms' joint implementation of organisational innovation and training may foster their adoption of environmental innovation (EI), and if this correlation falls within Porter Hypothesis (PH) framework. We study the relationship of complementarity between strategies of High Performance Work Practices (HPWP) and Human Resource Management (HRM) when EI adoption is the firms' objective, using an original dataset on 555 Italian industrial firms regarding EI, HPWP and HRM, coherent with the last CIS2006-2008 survey. Results show that sector specificity matter. The only case in which strict complementarity is observed in organisational change concerns CO 2 abatement, a relatively complex type of EI, but this is true only when the sample is restricted to more polluting (and regulated) sectors. This evidence is coherent with the Porter hypothesis: complementarity-related adoption of EI is an element of organisational change in firms that are subject to more stringent environmental regulations. Nevertheless, the fact that strict complementarity is not a diffuse factor behind the adoption of all environmental innovation indeed does not come as a surprise. At this stage in the development of green strategies, the share of eco-firms is still limited, even in advanced countries that are seeking tools for a new competitiveness. The full integration of EIs within the internal capabilities and firm's own assets is far from being reached, even in advanced and competitive industrial settings.

Desrochers and Haight (2014) examine two significant cases for which PH claims were once made: the British alkali industry and the (Tennessee) Copper Basin smelting operations. Our conclusions are: (1) the PH is based on a flawed understanding of how 'win win' innovations spontaneously emerge in competitive settings, (2) regulatory pressures were only one (and typically minor) factor, and (3) "strict and well designed" environmental regulations are unlikely to deliver superior outcomes to traditional property rights-based approaches.

\section{Applications of Porter's theory in China}

Regarding the cases in China, there are large geographical, historical and political differences between eastern, central and western regions in China. The development of the economy and society in eastern, central and western regions has resulted in obvious differences, particularly around environmental regulation and technological progress. By understanding the effects of environmental regulation on technological progress from the perspectives of different geographical areas in China, this study aims to promote innovation within the environmental management policy, strengthen environmental competitiveness of the industry and drive healthy and sustainable development of the economy and society in China.

There are lots of studies in China which support the Porter Theory:

Ramakrishnan et al. (2016) examine the relationships between environmental regulations, firms' innovation and private sustainability benefits using nine case studies of UK and Chinese firms. The results show that depending on firms' resources and capabilities, those that adopt a more dynamic approach to respond to environmental regulations innovatively and take a proactive approach to manage their environmental performance are generally better able to reap the private benefits of sustainability. 
Xie et al. (2017) use a slacks-based measure (SBM) and Luenberger Productivity Index, accounting for undesirable outputs, to evaluate the industrial "green" productivity growth rates of China's 30 provinces. By employing a panel threshold model and a province-level panel dataset during 2000-2012, empirical results show that both command-and-control and market-based regulation have a non-linear relationship with and can be positively related to "green" productivity but with different constrains on regulation stringency. Consequently, we find evidence to support the "strong" Porter Hypothesis that reasonable stringency of environmental regulations may enhance rather than lower industrial competitiveness.

Yuan et al. (2017) employs the panel data of 28 sub-sectors in China's manufacturing industry during 2003-2013, divides these sub-sectors into three groups - the high, medium and low eco-efficiency industries according to the ecoefficiency level, and explores the effects of environmental regulation on technical innovation ("weak" Porter hypothesis) and eco-efficiency ("strong" Porter hypothesis) respectively. The results show that the impacts of environmental regulation on technical innovation and eco-efficiency in the medium eco-efficiency group are both "U" type, indicating that moderately enhancing environmental regulation can achieve the win-win situation of economic and environmental performance in this group.

$\mathrm{Hu}$ et al. (2017) attempt to provide a model to compare the mediation roles of process innovation and product innovation in the $\mathrm{PH}$, using data from 35 industrial sectors in China from 2001 to 2010. Empirical results indicate that while both process innovation and product innovation mediate the causal link between environmental regulation and performance, product innovation has a slightly stronger mediation effect than process innovation.

Cai and $\mathrm{Li}$ (2018) use data collected from 442 Chinese firms to investigate the relationship among the drivers, eco-innovation behavior, and firm performance. The results reveal that certain factors contribute to the development of eco-innovation. Competitive pressure provides firms with the greatest incentive to adopt eco-innovation, followed by a market-based instrument, technological capabilities, customer green demand, and environmental organization capabilities. These findings support the "Porter hypothesis," and have several implications for both policy makers and business managers.

\section{Aspects regarding the application of the "Porter Theory"}

The above case studies show that environmental regulations and technological progress in enterprise do not exist in a single or definitive relationship. It also shows that the "innovation compensation effect" inspired by environmental regulation will not happen automatically. Whether or not the research show differences in support of the Porter Hypothesis, policy-makers agree that the strengthening of environmental regulation is beneficial to the environment and human health. Thus, policies to increase the demand of clean production products would promote businesses to make innovations on clean production technology. As there are differences in research methods, data and variable selection, academia has not formed a consensus on the impact of environmental regulation on technical progress. This paper aims to further identify the impact and influence mechanism of environmental regulation on industry technology progress in different areas in China.

This paper examines the relationship between environmental regulation and technological development in different regions of China. Industry data from 1999 to 
2012 using the DEA (Data Envelopment Analysis)-Malmquist productivity index were analyzed. The study applies the Malmquist DEA model and the Porter hypothesis to identify technology innovation opportunities to improve environmental performance, especially for the central and western regions of China.

\section{Methods}

In the second part of this study, a relevant mathematical model was constructed. The model was confirmed based on the strength of environmental regulation; restricting the incentive effect resulted in a weak will to produce technical progress.

The mathematical analysis results were used to obtain corresponding information. In this paper, the DEA (Data Envelopment Analysis)-Malmquist productivity index was analyzed for 30 Chinese provinces.

The Malmquist productivity index method is based on a measure of the progress of production technology and intensity of environmental regulation and used to estimate their relationship.

\section{DEA and Malmquist index}

In 1953, Malmquist, the Swedish economist and statistician, proposed the DEAMalmquist index. The index was originally used to analyze the trends of people's consumption in different periods. Fare et al. (1994) used the index to examine total factor productivity (TFP) in 1994, and applied the Shephard distance function to break it down further into the technology change (TC) and the technology efficiency change (TE). The method gained recognition from academia and was widely used. The principle of the DEA-Malmquist index and the computational formula is as follows:

Malmquist productivity index uses the directional output method or directional input method defined distance function, which describes multiple inputs, and multiple output production technology with no need to explain the specific standard of behavior. The advantages of this method are four fold: firstly, price information is unnecessary; secondly, it can be used in panel data analysis; thirdly, changes can be further decomposed into technology change and the technology efficiency change; fourthly, a specific production function hypothesis is not required. This article uses directional output variables to measure the total factor productivity (TFP), the distance function of the output variables is as follows $(E q .1)$ :

$$
D_{i}(x, y)=\inf \{\theta:(x, y / \theta) \in P(x)\}
$$

In Equation 1, $x$ is the input variable matrix, $y$ is the output variable matrix, $\theta$ is the directional output efficiency target for Farrell, $P(x)$ is production possibility. If $y$ is part of $P(x)$, then $D_{i}(x, y) \geq 1$. If $y$ is located on the boundary of $P(x)$ production possibility, then $D_{i}(x, y)=1$, which means production is technically efficient. If $y$ lies outside the $P(x)$ boundary, then $D_{i}(x, y)>1$, which means production is inefficient in technology.

The growth of the TFP Malmquist productivity index can be described by Equation 2: 


$$
M_{i}\left(x_{t+1}, y_{t+1} ; x_{t}, y_{t}\right)=\left[\frac{D_{i}^{t}\left(x_{t+1}, y_{t+1}\right)}{D_{i}^{t}\left(x_{t}, y_{t}\right)} \times \frac{D_{i}^{t+1}\left(x_{t+1}, y_{t+1}\right)}{D_{i}^{t+1}\left(x_{t}, y_{t}\right)}\right]^{1 / 2}
$$

In Equation 2, $\left(x_{t+1}, y_{t+1}\right)$ and $\left(x_{t}, y_{t}\right)$ represent the input and output vector of the period $(t+1)$ and the period $t$, respectively. $D_{0}^{t}$ and $D_{0}^{t+1}$ represent the distance function of the period $(t+1)$ and the period $t$, respectively, with reference of the period $t$ to technology, $T^{t}$.

Under the assumption of the constant scale reward condition, the Malmquist productivity index can be decomposed into technical efficiency change (TE) and technical progress index (TC). TE can be further decomposed into scale efficiency change index (SC) and pure technical efficiency index (PC). Therefore, the Malmquist productivity index can be broken down into:

$$
\begin{aligned}
& M_{i}\left(x_{t+1}, y_{t+1} ; x_{t}, y_{t}\right)=T E\left(x_{t+1}, y_{t+1} ; x_{t}, y_{t}\right) \times T C\left(x_{t+1}, y_{t+1} ; x_{t}, y_{t}\right) \\
& S C\left(x_{t+1}, y_{t+1} ; x_{t}, y_{t}\right) \times P C\left(x_{t+1}, y_{t+1} ; x_{t}, y_{t}\right) \times T C\left(x_{t+1}, y_{t+1} ; x_{t}, y_{t}\right)
\end{aligned}
$$

In Equation 3, the technical efficiency change (TE) in terms of economics is: every observation and object are within chasing degree from the period $t$ to the period $(t+1)$ and to the best production frontier border.

The economic meaning of technological progress (TC) is: the movement of the technology boundary from the period $t$ to the period $(t+1)$. Scale efficiency change (SC) is used as the foundation to judge whether the decision-making units are in optimum condition. When $\mathrm{SC}=1$, it means economies of scale exist, when $\mathrm{SC}<1$, diseconomies of scale exist. Pure technical efficiency (PC) is the efficiency of the organization without a scale factor. If $\mathrm{PC}=1$, the production mode has a pure efficiency or takes the form of a pure efficiency production. If $\mathrm{PC}<1$, it is an indication the decision-making unit failed to produce in an efficient way, or in a pure technical efficiency way.

\section{Model for environmental regulation influence on technological progress}

The key to establishing the Porter Hypothesis is whether the environmental regulation can motivate enterprises to carry out technical innovation, and then reduce the cost of production through the "innovation compensation". The existing literature at home and abroad pay more attention to the influence of environmental regulation on technical innovation, but pay less attention to the stimulation of the environmental regulation to the enterprise or industry's management system innovation. While the DEA-Malmquist productivity index decomposes technological progress into the technology change index and the technology efficiency change index, the technology change index mainly measures the ability of technological innovation, the technical efficiency index mainly measures the management system innovation. Therefore, it provides the premise to objectively evaluate the influence of environmental regulation on technical progress, and provides a theoretical basis to judge the effect of environmental regulation on technology innovation and management innovation.

According to the usual practice in the available literature (Zhang and Lu, 2011), in order to examine the relationship between the productivity in different areas and environmental regulation, the following estimation model and method is used: 
First of all, verify the effect of the environmental regulation on technical progress as a whole, this model is as follows:

$$
M_{i t}=C_{i}+\beta_{1} E G_{i t}+\beta_{2} A S_{i t}+\varepsilon_{i}
$$

Among the terms, i represents $1,2, \ldots 30$ provinces and regions, t represents the year, $\mathrm{t}=1999, \ldots, 2012$ (below), $\mathrm{M}$ is the Malmquist index for measuring technical progress, which is made up of the technology change (TC) and the technology efficiency change (TE), $\beta$ represents estimated parameters, $E G_{i t}$ represents the environmental regulation intensity of i province in t year, namely the ratio of the total amount of investment for industrial pollution control and the main business cost of the industrial enterprises above a certain size, $A S_{i t}$ represents the average size of large industrial enterprises of $\mathrm{i}$ province in t year.

Secondly, consider the environmental regulation's effect on the two component indices of the Malmquist index, the two models are as follows:

$$
\begin{aligned}
& T C_{i t}=C_{i}+\beta_{1} E G_{i t}+\beta_{2} A S_{i t}+\varepsilon_{i} \\
& T E_{i t}=C_{i}+\beta_{1} E G_{i t}+\beta_{2} A S_{i t}+\varepsilon_{i}
\end{aligned}
$$

This article successively conducted regression analysis for the three equations (Eqs. 4, 5 and 6), tests of the influence of environmental regulation on technical progress. During the model selection, choose the fixed effect model or random effects model according to the Hausman test results.

\section{Raw data source}

For this study, data on industry output, fixed investment, employees, main business cost and average size of industrial enterprises directly from "The China Statistical Yearbook" during 1999 to 2013 was used. Data on total investment of industrial pollution control comes from "The China Environment Statistical Yearbook". Due to lack of average employee data in large industrial enterprises before 2000 in the statistical yearbook, this paper consults the method of Zhang and Lu (2011), and uses the ratio of industrial added value and the productivity of the overall industrial member to supplement the average industrial employee data before 2000. When measuring change in technological progress, as for the output variables of DEA, 1999 was used as the base period. In this research, the provincial industrial GDP was used as the data deflator. For the data on environmental regulation intensity, an average of 2006 and 2008 data was used to forecast 2007 data, as data is published every two years.

\section{Variables}

This paper aims to study the effect of environmental regulation on technical progress and to test the applicability of the Porter Hypothesis in China. In order to carry out empirical research, the following variables were selected as indicators of technical progress and environmental regulation:

In order to measure the technical progress in China of 30 provinces in 1999-2012 using the Malmquist productivity index, the industrial sector's input and output data of the 30 provinces was used. This article selects the industrial output of 30 provinces 
during 1999 to 2012 as output variables, and selects the fixed capital investment of these provinces as capital investment. In addition, the labor input should be measured by the labor time, but due to lack of data, all the employees of state-owned industrial enterprises and non-state-owned industrial enterprises above a certain size in the provinces and regions are selected as labor input. The descriptive statistical characteristics of variables is shown in Table 1.

Table 1. The descriptive statistical characteristics of variables

\begin{tabular}{c|c|c|c|c|c|c|c}
\hline Variable & Units & Samples & Average & Median & Maximum & Minimum & SD \\
\hline Industrial output & 100 M Yuan & 420 & 3774.32 & 2194.34 & 25810.07 & 59.43 & 4426.28 \\
Fixed investment & 100 M Yuan & 420 & 4578.34 & 2512.13 & 31255.98 & 117.15 & 5201.14 \\
Employees & 100,000 & 420 & 241.79 & 150.12 & 1568 & 9.62 & 263.79 \\
\hline
\end{tabular}

The average, median and deviation values of each variable are produced from calculations of according to the "China Statistical Yearbook (1999-2013)", and the rest of the variable values are directly from the Statistical yearbooks

As for the selection of variables of environmental regulation intensity (EG), domestic scholars such as Xie et al. (2017) used the total amount of investment for industrial pollution control.

Ramakrishnan (2016) used the inspection times by the environmental regulation institution of business pollution treatment and Zhang et al. (2010) used the average operation costs of the pollution-treatment facilities for industrial water and gas waste. The above indicators have a few shortcomings. It is generally believed that the greater the intensity of environmental regulation, the more investment for pollution control, but this conclusion is only possible under the condition of constant pollution control cost. Therefore, based on the availability and relative perfection of the data, our research used Zhang and Lu's (2011) selection. The index for environmental regulation intensity and the ratio of total industrial pollution control investment to main business cost of large industrial enterprises in 30 provinces was used as the variable for the intensity of environmental regulation. Further, distinct from other research studies, this study used the size of a relative value. Prior to 2004, "main business cost" was not listed in the statistical yearbook. Thus, "cost of products sold" was selected as cost data prior to 2004 and, after 2004, "main business cost" replaced the "cost of products sold".

Due to the difficulty of accessing data, this paper only selects the average size of industrial enterprises (AS) as the control variables. It is value is the ratio of total assets to the number of units of the industrial enterprises above a certain size.

\section{Results}

\section{Technological progress index and its decomposition results}

In this study, DEAP2.1 software was used to calculate the progress index and the data decomposition index of China's industrial sector in 30 provinces (except Tibet) for 14 consecutive years from 1999 to 2012. It was concluded that the total factor productivity and technological progress, technical efficiency, pure technical efficiency, and economy scale are 4 decomposition variables based on the Malmquist productivity 
index. To reach this stage, Equations 1, 2 and 3 were used to obtain the Malmquist index and its decomposition index for the industrial sector of China's 30 provinces (Table 2).

Table 2. The Malmquist index and its decomposition index for industrial sectors of 30 Chinese provinces (1999-2012)

\begin{tabular}{|c|c|c|c|c|c|}
\hline Region & $\begin{array}{c}\text { The total factor } \\
\text { productivity (TFP) }\end{array}$ & $\begin{array}{l}\text { Technological } \\
\text { progress (TC) }\end{array}$ & $\begin{array}{c}\text { Technical } \\
\text { efficiency (TE) }\end{array}$ & $\begin{array}{l}\text { Pure technical } \\
\text { efficiency (PC) }\end{array}$ & $\begin{array}{c}\text { The scale } \\
\text { efficiency (SC) }\end{array}$ \\
\hline Beijing & 1.106 & 1.101 & 1.005 & 1.008 & 0.997 \\
\hline Tianjin & 1.077 & 1.051 & 1.025 & 1.020 & 1.005 \\
\hline Hebei & 1.064 & 1.068 & 0.997 & 1.007 & 0.990 \\
\hline Liaoning & 1.074 & 1.067 & 1.007 & 1.004 & 1.002 \\
\hline Shanghai & 1.084 & 1.074 & 1.009 & 1.009 & 1.000 \\
\hline Jiangsu & 1.031 & 1.046 & 0.986 & 1.006 & 0.979 \\
\hline Zhejiang & 1.027 & 1.050 & 0.978 & 0.992 & 0.986 \\
\hline Fujian & 1.005 & 1.034 & 0.972 & 0.976 & 0.996 \\
\hline Shandong & 1.025 & 1.046 & 0.980 & 1.000 & 0.980 \\
\hline Guangdong & 1.022 & 1.016 & 1.006 & 1.000 & 1.006 \\
\hline Hainan & 1.168 & 1.147 & 1.018 & 1.000 & 1.018 \\
\hline $\begin{array}{c}\text { The eastern } \\
\text { average }\end{array}$ & 1.062 & 1.064 & 0.998 & 1.002 & 0.996 \\
\hline Shanxi & 0.979 & 0.995 & 0.984 & 0.981 & 1.003 \\
\hline Jilin & 1.092 & 1.080 & 1.011 & 1.003 & 1.008 \\
\hline Heilongjiang & 1.020 & 1.040 & 0.980 & 0.981 & 0.999 \\
\hline Anhui & 1.056 & 1.087 & 0.971 & 0.972 & 0.999 \\
\hline Jiangxi & 1.074 & 1.095 & 0.980 & 0.975 & 1.006 \\
\hline Henan & 1.012 & 1.020 & 0.992 & 1.005 & 0.987 \\
\hline Hubei & 1.058 & 1.070 & 0.989 & 0.995 & 0.994 \\
\hline Hunan & 1.068 & 1.084 & 0.985 & 0.989 & 0.996 \\
\hline $\begin{array}{l}\text { The central } \\
\text { average }\end{array}$ & 1.045 & 1.059 & 0.987 & 0.998 & 0.999 \\
\hline Inner Mongolia & 1.162 & 1.138 & 1.021 & 1.010 & 1.011 \\
\hline Guangxi & 1.094 & 1.094 & 1.000 & 0.994 & 1.006 \\
\hline Chongqing & 1.107 & 1.097 & 1.009 & 1.003 & 1.006 \\
\hline Sichuan & 1.082 & 1.087 & 0.996 & 1.003 & 0.993 \\
\hline Guizhou & 1.077 & 1.089 & 0.989 & 0.980 & 1.009 \\
\hline Yunnan & 1.074 & 1.108 & 0.970 & 0.973 & 0.996 \\
\hline Shaanxi & 1.131 & 1.098 & 1.030 & 1.021 & 1.008 \\
\hline Gansu & 1.035 & 1.036 & 0.999 & 0.991 & 1.008 \\
\hline Qinghai & 1.151 & 1.103 & 1.043 & 1.000 & 1.043 \\
\hline Ningxia & 1.111 & 1.093 & 1.016 & 0.992 & 1.024 \\
\hline Xinjiang & 1.139 & 1.116 & 1.020 & 1.015 & 1.005 \\
\hline $\begin{array}{l}\text { The western } \\
\text { average }\end{array}$ & 1.106 & 1.096 & 1.008 & 0.998 & 1.010 \\
\hline $\begin{array}{c}\text { The national } \\
\text { average }\end{array}$ & 1.072 & 1.074 & 0.999 & 0.997 & 1.002 \\
\hline
\end{tabular}


As seen in Table 2, the national average for the total factor productivity of 30 provinces in the sample interval is 1.072, which is greater than 1; total factor productivity is growing. As seen from its decomposing index, the technical change index is 1.074 , also greater than 1 . The technical efficiency is 0.999 and exceeds pure technical efficiency. Therefore, the technological progress changes caused the growth of the total factor productivity, and the technological progress changes are mainly caused by the scale efficiency.

Next is the pure technical efficiency. The technology change index is 1.074 , this means that the technological progress has an average annual growth of $7.4 \%$. This indicates technology as a whole is progressing nationally within time scope of this study.

This study divided the country's 30 provinces into three geographical regions: the eastern, central and western regions, to examine the growth of technological progress.

As seen in Table 2, the total factor productivity of the eastern, central and western regions is consistent with the national total factor productivity. They all exhibit a growing trend within the sample range, and the growth of the total factor productivity is mainly caused by technological progress change. However, it was found that the western region of the total factor production led the eastern and central regions.

From the perspective of the decomposition variables, the technological progress and technical efficiency index's decomposition index for the western region is higher than for the Midwestern region. The numerical results show that both the total factor productivity change and the growth of the technical progress in western China is the largest from 1999 to 2012. At the provincial level, the total factor productivity change in Hainan province (the index is 1.168) is the largest within the sample period, followed by Inner Mongolia (total factor productivity index is 1.162); only in the central region of Shanxi Province (index is 0.979 ) is the total factor productivity less than 1 . The total factor productivity of other provinces is greater than 1. In addition, looking at the decomposing index, only the technology change index in Shanxi Province is less than 1, at 0.995 .

\section{The environmental regulation and the regression of the technological progress index and its decomposition index}

On the whole, Table 3 shows the regression results of the environmental regulation and technological progress of 30 provinces.

Table 3. The estimated results of the environmental regulation model to industrial technological progress

\begin{tabular}{c|c|c|c}
\hline & Equation 4 (TFP) & Equation 5 (TC) & Equation 6 (TE) \\
\hline C & 1.071 & 1.077 & 1.006 \\
EG & 2.887 & 2.732 & 0.0594 \\
AS & 0.0002 & -0.002 & -0.0009 \\
Model & FE & FE & FE \\
Hausman test & 21.46 & 6.36 & 8.86 \\
P>chi2 & 0.0000 & 0.0415 & 0.0119 \\
\hline
\end{tabular}


It can be seen that the regression intercept of Equations 4, 5 and 6 is significantly greater than 1. Overall, when the average size of the controlled variable enterprise is in a certain case, the three regression equations show that environmental regulation has positive influence on technical progress of the industrial sector. Considering the latency of environmental regulations on enterprise technological progress, this article also carried out regression testing of the technological progress index and environmental regulation of the phase 1 . The results were similar to the no-lag situation; thus, they are not listed in Table 3.

Generally, over the past 14 years from 1999 to 2012, under the constant scaling of industrial enterprise, environmental regulation has promoted technological progress. When environmental regulation strengthens by $1 \%$, technological progress increases by $2.73 \%$. In addition, when environmental regulation strengthens by $1 \%$, the technical efficiency index rises $0.059 \%$. Although the increase is small, technical efficiency is promoted. On the whole, the change of the environmental regulation intensity had an obvious positive role in promoting industrial technological progress for the overall nation. It was found that the total factor productivity increases by $2.887 \%$ when the intensity of the environmental regulation rises by $1 \%$.

Because there is a big gap between the Chinese provinces in economic level, industrial structure and environmental regulation policy, the 30 provinces were divided into three groups: eastern, central and western provinces, each group consisting of the variables in Table 4. Table 4 shows that the intensity of the environmental regulation on different regions is different for the sample time period.

Table 4. The estimated results of the environmental regulation model on industrial technological progress in the eastern, central and western regions

\begin{tabular}{c|c|c|c|c}
\hline & & Equation 4 (TFP) & Equation 5 (TC) & Equation 6 (TE) \\
\hline \multirow{4}{*}{$\begin{array}{c}\text { The eastern } \\
\text { region }\end{array}$} & $\mathrm{C}$ & 1.037 & 1.050 & 1.0001 \\
& $\mathrm{EG}$ & 7.1411 & 7.039 & -0.644 \\
& $\mathrm{AS}$ & 0.014 & 0.007 & 0.0029 \\
& Model & $\mathrm{FE}$ & $\mathrm{FE}$ & $\mathrm{RE}$ \\
& Hausman test & 16.26 & 6.41 & 1.35 \\
\hline \multirow{4}{*}{ The central } & $\mathrm{P}>$ chi2 & 0.0003 & 0.0406 & 0.5103 \\
\hline region & $\mathrm{C}$ & 1.074 & 1.095 & 0.993 \\
& $\mathrm{EG}$ & -6.884 & -4.911 & -1.61 \\
& $\mathrm{AS}$ & -0.005 & -0.013 & 0.0025 \\
& Model & $\mathrm{RE}$ & $\mathrm{RE}$ & $\mathrm{RE}$ \\
& Hausman test & 4.82 & 4.08 & 0.03 \\
& $\mathrm{P}>$ chi2 & 0.0896 & 0.1301 & 0.9835 \\
\hline The western & $\mathrm{C}$ & 1.155 & 1.128 & 1.041 \\
region & $\mathrm{EG}$ & -3.06 & -1.08 & -2.496 \\
& $\mathrm{AS}$ & -0.016 & -0.01 & -0.008 \\
& Model & $\mathrm{FE}$ & $\mathrm{RE}$ & $\mathrm{RE}$ \\
& Hausman test & 15.47 & 2.44 & 5.54 \\
& $\mathrm{P}>$ chi2 & 0.0004 & 0.2956 & 0.0626 \\
\hline
\end{tabular}


As seen in Table 4, the technological progress of the eastern region is the most significant during the sample period. Generally, under the premise that average enterprise size remains the same, the total factor productivity index increases by $7.14 \%$ when the environmental regulation strengthens by one percent for the eastern region.

The growth of the total factor productivity is primarily caused by the change in technological progress. The technology of the eastern region is progressive during this period of time, and the technology progress increases by $7.04 \%$ when the environmental regulation strengthens by $1 \%$. However, during this period, the change in technical efficiency decreased. The estimated result of the environmental regulation intensity on the technological progress of the central region shows that the total factor productivity, technical change and the technical efficiency index declined. During this time, although nationally industry made great progress on technology, due to an increase in intensity of environmental regulation, technological progress decreased in the central region.

From the results of the regression on environmental regulation and technological progress in the western region, it can be found that increasing intensity of environmental regulation blocks industrial technology progress. With improvement of regulation, the total factor productivity, the technical progress and the technical efficiency all decrease. However, the effect of the environmental regulation is not as strong as it is in the central region.

\section{Discussion}

In this paper, the results of an empirical study show that the impact of environmental regulation policy on technological innovation varies in different regions and different levels of economic development.

(1) The growth of total factor productivity is mainly caused by the change of technological progress. Industrial environmental regulation has positive impact at the national level on technological progress. However, the relationship between environmental regulation and technological progress showed significant differences at the regional level.

(2) In the eastern and central regions, when the intensity of environmental regulation increased by $1 \%$, the corresponding increase in technical progress in Eastern China is $7.04 \%$, which supports the Porter hypothesis. With the increase of intensity of environmental regulation, the production technology progress rate gradually increases.

(3) In the central and western regions, when the intensity of environmental regulation increased by $1 \%$, technical progress was reduced by $4.91 \%$ and $1.08 \%$ respectively, and Porter's hypothesis is not supported. Under the influence of environmental regulations, the Porter hypothesis is not supported in a relatively backward area, and can be well supported in more developed areas.

This result gives new enlightenment, as Lenovo stated, "some internal relations exist between the Porter hypothesis and the hypothesis of the environmental Kuznets curve". In turn, the environmental Kuznets curve hypothesis for the "Porter hypothesis" in different regions can be used to obtain support of the differences to make a reasonable explanation.

An empirical study of Grossman and Krueger in 1991 found an interesting phenomenon: the relationship between environmental pollution and economic development was an inverted $U$ curve relationship. Because it resembles the Kuznets curve, described by the income gap between economic growth, and shows the inverted 
$\mathrm{U}$ curve relationship, it is known as the environmental Kuznets curve. The environmental Kuznets curve shows that at an early stage, pollutant emissions increased with economic growth; environmental quality worsened in this situation. When the economy develops to a certain level, such as emission peak (a), but after the start of decreased pollutant emission along with economic growth, then environmental quality improves.

For a region or country in the beginning of economic development (before $b$ ), economic development is the first priority. Thus, it is more difficult to use the Porter hypothesis to describe the situation, namely the implementation of strict environmental regulation. It is not easy to stimulate environmental technology innovation for enterprises.

Resistance to environmental regulation, implementation difficulties of environmental technology innovation, and lack of motivation cause increasing environmental pollution-- this is a good explanation of the left side of the EKC curve described in the trend.

According to the Porter hypothesis, environmental regulation has a positive impact on technological innovation and competitiveness, but it is conditional. Only when a country or region's economic development level reaches a certain extent, is it possible to use the Porter hypothesis to describe the situation. When economic development reaches a high level (b), and environmental pollution reaches a very serious degree (point a), "pollution first, treatment later", does the implementation of strict environmental regulation policy become imperative. Then, strict environmental regulation can effectively stimulate or force the enterprise to carry out technical innovation, to replace non clean technology used in the past.

The previous technology can not meet the requirements of environmental regulation and emission reduction, and new clean technology may lead to innovation compensation in the economy, or improve business competition-- this is a good explanation of the right curve of the EKC to describe the environmental pollution degradation trend.

\section{Conclusion}

This research examines the relationship between environmental regulation and technological development in different regions of China. Industry data from 1999 to 2012 using the DEA (Data Envelopment Analysis)-Malmquist productivity index were analyzed. The conclusions are as follows :

(1) The total factor productivity growth is mainly caused by change in technological progress. The environmental regulation of industry had a positive effect on technical progress at the national level. However, the relationship between environmental regulation and technological progress showed significant differences at the regional level. For the well-developed eastern regions, for every $1 \%$ increase in strength of environmental regulation, there was a corresponding $7.04 \%$ increase in technology progress in eastern China. However, in central and western China, for every 1\% increase in strength of environmental regulation, technology progress declined by $4.91 \%$ and $1.08 \%$, respectively. The Porter hypothesis is well supported by data from the advanced eastern regions, while not fully supported by data from the underdeveloped central and western regions. For the central and western regions, 
various reasons that cause deviations from the Porter Theory have been determined using the Environmental Kuznets Curve (EKC).

(2) The results imply that the relevant actions from the government's future management should include: The Chinese government should further increase the intensity of environmental regulation to stimulate enterprise technology innovation. On one hand, this allows enterprises to achieve pollution reduction and control of sewage treatment at a high level. On the other hand, this may improve the productivity and international competitiveness.

(3) The government should pay more attention to optimizing forms of environmental regulation according to local conditions. Flexible use of environmental taxes, emissions trading, recycling systems, green consumption, sewage charge refund mechanism, tax subsidies, and other means of environmental regulation give businesses the flexibility to make more economical choices to achieve environmental regulation requirements, thus making the decline phase of the U-type curve more gentle. Actions to promote the inflection point of the U-curve to occur as soon as possible should be taken. This act to break the U-curve, and to ensure that trends follows the distinct "U" curve rising stage, is important for the realization of China's environmental protection and intensive economic growth. A "win-win" situation is needed to provide support.

\section{REFERENCES}

[1] Albrizio, S., Kozluk, T., Zipperer, V., (2017): Environmental policies and productivity growth: Evidence across industries and firms. - Journal of Environmental Economics and Management 81: 209-226.

[2] Antonioli, D., Mancinelli, S., Mazzanti, M. (2013): Is environmental innovation embedded within high-performance organisational changes? The role of human resource management and complementarity in green business strategies. - Research Policy 42(4): 975-988.

[3] Cai, W. G., Li, G. P. (2018): The drivers of eco-innovation and its impact on performance: Evidence from China. - Journal of Cleaner Production 176: 110-118.

[4] Carney, M., Duran, P., van Essen, M., Shapiro, D. (2017): Family firms, internationalization, and national competitiveness: Does family firm prevalence matter? Journal of Family Business Strategy 12: 123-136.

[5] Chang, M. C. (2013): Environmental regulation, technology innovation, and profit: a perspective of production cost function. - Theoretical Economics Letters 03(06): 297301.

[6] De Santis, R., Jona Lasinio, C. (2016): Environmental policies, innovation and productivity in the EU. - Global Economy Journal 16(4): 1557-1568.

[7] Desrochers, P., Haight, C. E. (2014): Squandered profit opportunities? Some historical perspective on industrial waste and the Porter Hypothesis. - Resources, Conservation and Recycling 92: 179-189.

[8] Fare, R., Grosskoph, S., Norris, M., Zhang, Z. (1994): Productivity growth, technical progress, and efficiency change in industrialized countries. - American Economic Review 84: 66-83.

[9] Grossman, G. M., Krueger, A. B. (1991): Environmental impacts of a north American free trade agreement. - Social Science Electronic Publishing 8(2): 223-250.

[10] Hu, D., Wang, Y. D., Huang, J. S. Huang, H. Y. (2017): How do different innovation forms mediate the relationship between environmental regulation and performance? Journal of Cleaner Production 161: 466-476. 
[11] Jia, R. Y., Wei, J. C., Zhao, D. T. (2013): The environmental regulation and the production technology progress: based on the empirical analysis of the perspective of the regulation tools. - Journal of University of Science and Technology of China 43(3): 217222.

[12] Lundren, T., Zhou, W. C. (2017): Firm performance and the role of environmental management. - Journal of Environmental Management 203: 330-341.

[13] Manello, A. (2017): Productivity growth, environmental regulation and win-win opportunities: The case of chemical industry in Italy and Germany. - European Journal of Operational Research 4: 733-743.

[14] Porter, M. E. (1991): Towards a dynamic theory of strategy. - Strategic Management Journal 12(S2): 95-117.

[15] Porter, M. E., Vander L. C. (1995): Toward a new conception of the environmentcompetitiveness relationship. - Journal of Economic Perspectives 9: 97-118.

[16] Ramakrishnan, R., He, Q. L., Andrew, B., Abby., David, G. (2016): Environmental regulations, innovation and firm performance: A revisit of the Porter hypothesis. Journal of Cleaner Production 43: 79-92.

[17] Ramakrishnan, R., Usha, R., Bentley, Y. M. (2017): The debate on flexibility of environmental regulations, innovation capabilities and financial performance - a novel use of DEA. - Omega 75(C): 131-138.

[18] Xie, R. H., Yuan, Y. J. Huang, J. J. (2017): Different types of environmental regulations and heterogeneous influence on "green" productivity: evidence from China. - Ecological Economics 132: 104-112.

[19] Yuan, B. L., Ren, S. G., Chen, X. H. (2017): Can environmental regulation promote the coordinated development of economy and environment in China's manufacturing industry? - A panel data analysis of 28 sub-sectors. - Journal of Cleaner Production 149: $11-24$.

[20] Zhang, C., Lu, Y. (2011): Intensity of the environmental regulation and development of production technology. - Economic Research Journal 2: 113-124.

[21] Zhang, C., Yu, T. S., Guo, L. (2010): Has environmental regulation affected China's industrial productivity? The empirical test based on DEA and co-integration analysis. Economic Theory and Business Management 3: 12-16. 